\title{
Techno-Economic Feasibility Analysis of Concentrated Solar Thermal Power Plants as Dispatchable Renewable Energy Resource of Pakistan: A case study of Tharparkar
}

\author{
Kush Lohana, Aqeel Raza, Nayyar Hussain Mirjat, Suhail Ahmed ShaikhShoaib Ahmed \\ Khatri and Wajahat Shabbir \\ Department of Electrical Engineering, Mehran University of Engineering \& Technology, \\ Jamshoro 76062, Pakistan \\ kushlohana1998@gmail.com, razaaqeel3@gmail.com, \\ nayyar.hussain@faculty.muet.edu.pk, suhailshaikh393@gmail.com, \\ shoaib.ahmed@faculty.muet.edu.pk, korejowajahatshabbir@yahoo.com
}

\begin{abstract}
Pakistan is identified to be one of the next-11 the top emerging economies of the world after the BRICS. This emphasizes the establishment of a competitive electricity market that can fulfil the demand of the country considering the environmental concerns. In this scenario reliability of power is something that cannot be compromised. Dispatchable power stations play a major role in balancing supply and demand; this balance is essential for maintaining the power cuts free country. All dispatchable power stations incorporate some form of storage particularly thermal or chemical (i.e. a stored fuel). Earlier dispatchable power was regarded as the generation which can start quickly and meet the peak demand requirements but arrival of renewables in power system has increased worth of its presence since it has just not to supply peak demand but also to meet during the unavailability of other renewable energy sources because of their intermittent behavior meanly at times of dark hours and slow wind speed. This study considers the viability of Concentrated Solar Thermal Power in Pakistan and thoroughly analyses several characteristics i.e., Availability of fuel, water, road and communication network, flexibility and environmental impacts of the technology for the cite of Tharparkar.
\end{abstract}

\section{Keywords}

CSP, Renewables, Intermittency, Dispatchable Power.

\section{Introduction}

A trembling economy like Pakistan beseeches foreign investments to uplift the wrecked industrial sector and efforts need to be taken with an intense level of urgency. In the list of top withering factors to economy, Power outages and high electricity prices are at second preceded by terrorism. Along with smooth legal pathways, reliability of power and transparency of tariff index are key driving forces for the Ease of doing business in any country(World Bank Group, 2018). (World Bank Group, 2018) In such a scenario, we cannot rely on imported fuel to be the backbone of our power system which not only puts financial burden but also prone to Geopolitical Scenario and Exchange rates. This can be realized from the fact the Pakistani Rupee has depreciated about 50\% from 2018-20.

During this century, we will have to address the challenge of deeply transforming the world energy system to make it much more sustainable and environmentally friendly than the one we currently have. To achieve this, we will have to substantially increase the market penetration of all types of renewable energy technologies.

Solar Thermal Power plant is particularly something very attractive with a genuine notion. Solar Thermal power plant is also known as Concentrated Solar Power plant (CSP) is the technology of energy extraction, in which sunlight is concentrated at one point on liquid, heat converts liquid into pressurized gas which rotates the turbines, that in turn provides rotational mechanical power to a generator for the production of electricity.

From Solar technologies, Photovoltaics (PV) has already been commercialized and gives a major share in today's world energy requirement however Concentrated solar thermal has yet to go through 
the learning curve and seems to be a major contributor as a baseload and dispatchable resource in energy mix generation of future(Lilliestam et al., 2018).

Per unit of electricity is a major consideration when considering any new technology. A significant decline of $26 \%$ year to year in the cost of Concentrated solar thermal power, twice than the rate seen in onshore wind and PV and has dropped 46\% since 2010(Renewable Power Generation Costs In 2018, 2019). Frank Dinter suggests these costs for parabolic trough and solar towers will fall between $33 \%$ and $37 \%$ by 2025 , compared to 2015 , owing largely to market developments and technology advancements("China Puts Online Pioneering Large-Scale CSP Project," 2018). Decreasing Levelized Cost of Electricity (LCOE) and increasing capacity factor support its deployment.

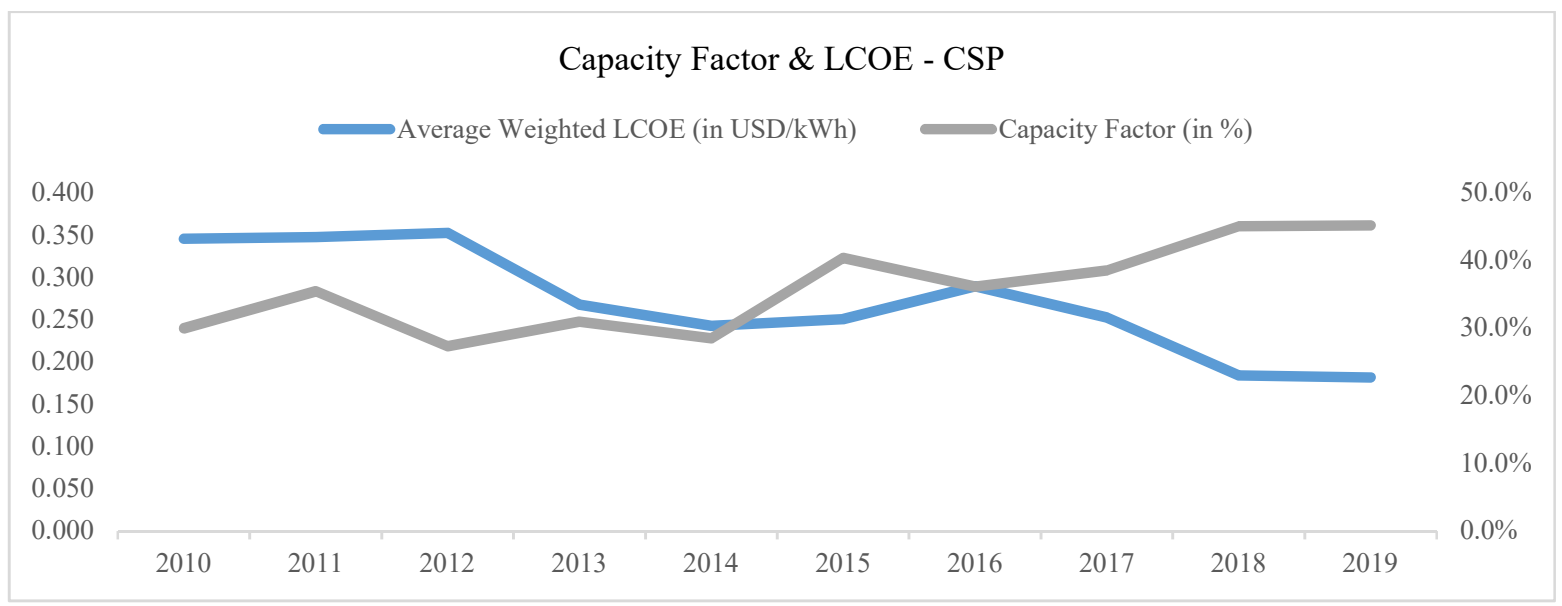

Figure 1. LCOE \& Capacity Factor - CSP [5]

CSP is growing as a very mature technology; India, China, and Iran, three of four neighbour countries of Pakistan have already adopted its commercialization. There is also financial feasibility of CSP plants in Pakistan as the Levelized Cost of energy is significantly low(Soomro et al., 2019).

Pakistan is a potential country for extracting solar energy as it receives plenty of Direct Normal irradiance (DNI) shown in Figure 2. DNI Map of Pakistan ("Pakistan_DNI_mid-size-map_156x163mm300dpi_v20170301.png (1842×1925),").

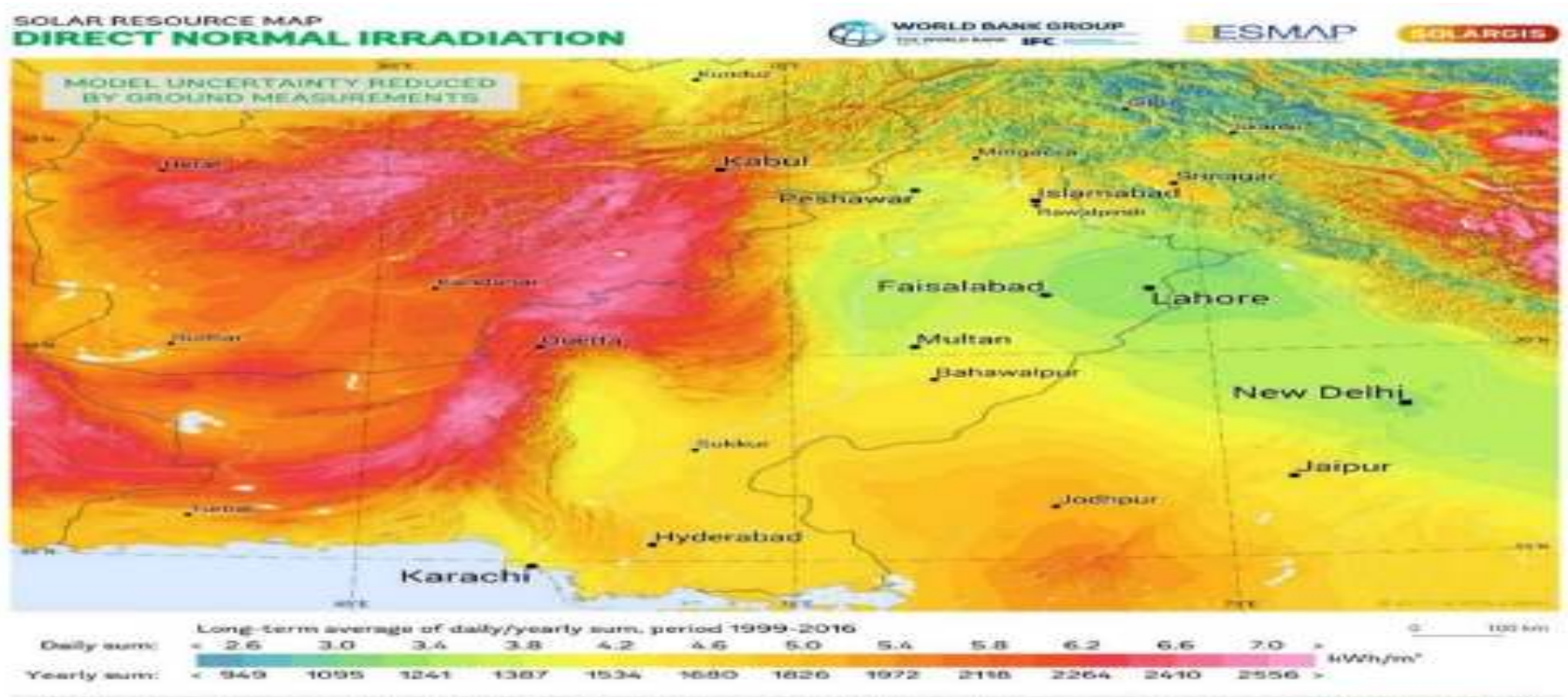

Figure 2. DNI Map of Pakistan (“Pakistan_DNI_mid-size-map_156x163mm-300dpi_v20170301.png (1842×1925),") 
Studies (Mehos et al., 2016) and (Lilliestam, Bielicki, \& Patt, 2012) suggest that it results in higher capacity factor and greater dispatchability when the Concentrated solar thermal (CSP) plant is given with Thermal Energy Storage (TES) and its LCOE is not that affected.

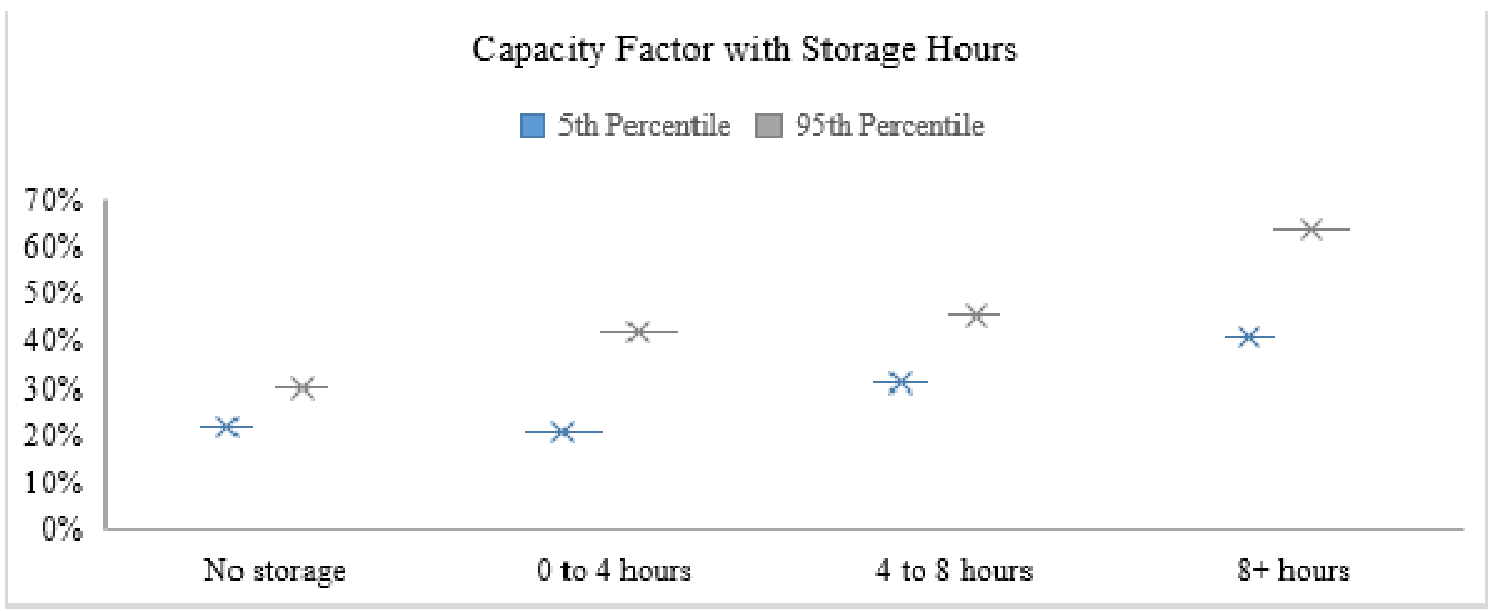

Figure 3. Capacity Factor with Storage Hours(Renewable Power Generation Costs in 2019, 2020)

It becomes a unique source of solar energy in its output that can be shifted over time and controlled in response to system requirements, allowing for the provision of a wide range of grid services. Unlike regular perception, CSP has no competition with Solar PV due to difference to their role, CSP with Thermal Energy Storage rather supports its commercialization by being a remedy to its intermittency(Hamilton, Husted, Newman, Braun, \& Wagner, 2019). If dispatchability and thus storage is considered then Concentrated solar thermal is both technically and financially preferable over commercialized renewables(Rahouma et al., 2017).

CSP offers an extra advantage as Glass, being used for focusing purpose, can be recycled $100 \%$ so this does not end up life leaving with no useable or difficult to utilize residue.

This review suggests that Concentrated Solar Thermal can play a major role in the future Energy Mix of the world and Pakistan can avail it quite with ease since it is blessed with high Direct Normal Irradiance and other conditions like humidity, terrestrial slope, and land availability are also supporting.

\section{Proposed Location}

First and foremost, information about a power plant is its location. Sites of Sindh and plain areas of Baluchistan are encouraging for the small scale projects of CSP and Parabolic Trough as a more viable technology to be adopted for commercialization. There is a variety of technologies for Concentrated solar thermal and few of them like parabolic dish need quite a low amount of water or air cooling can also be implied(Soomro et al., 2019). In the study(Saleem \& ul Asar, 2014) a case of Nara Desert, Nawabshah is undertaken for the study and Geospatial toolkit, TRNSYS Tool and STEC Library were used to produce results. The study suggests that solar thermal power can compete well with conventional fossil fuel and renewable energy power plants in the energy market of Pakistan.

Site selection is a very crucial task and the distinct land of Tharparkar bordering with India in south and east and with districts of Badin, Mirpurkhas, and Umerkot in west and north, has many benefits over other areas discussed in Section Error! Reference source not found. 


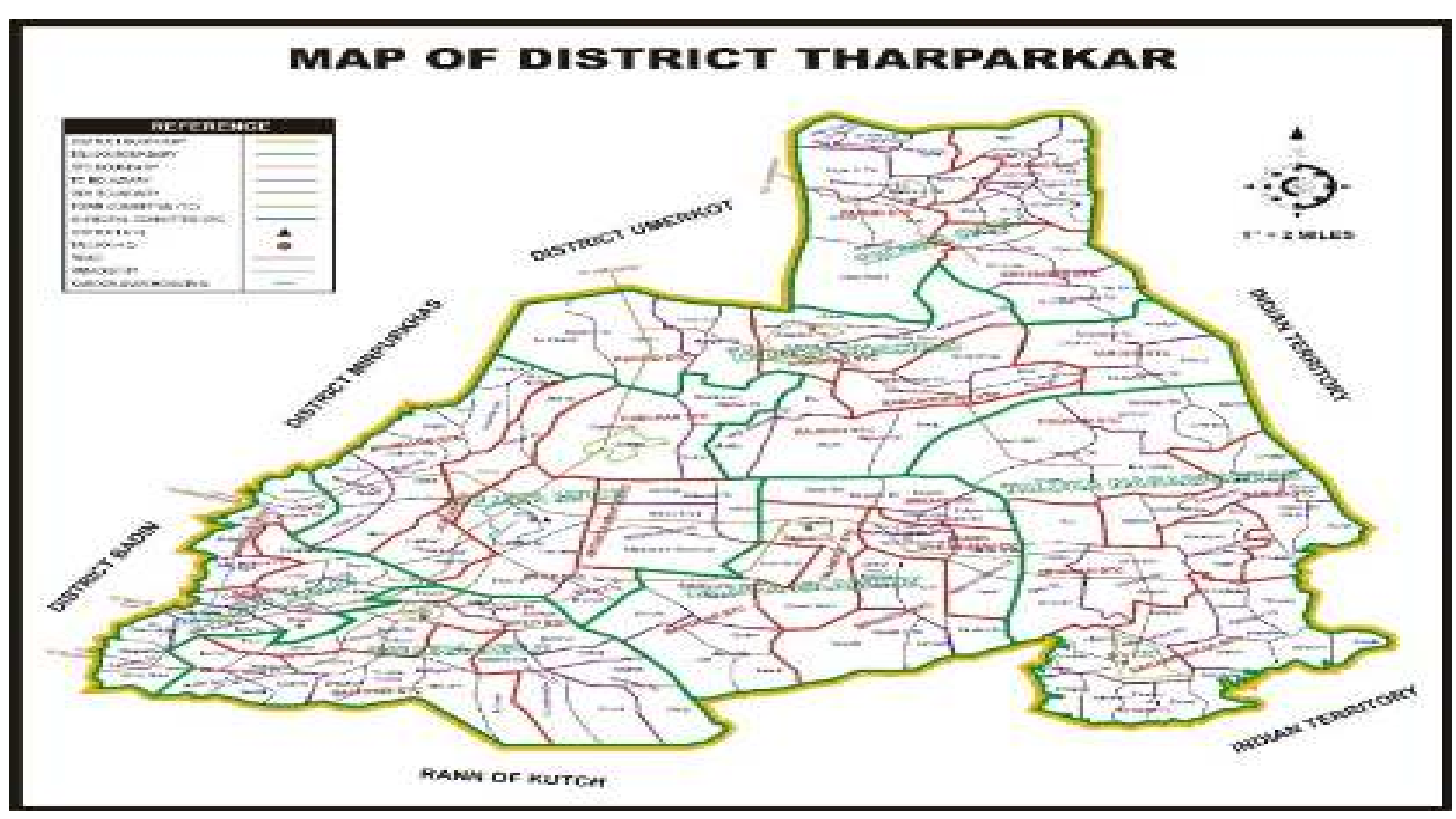

Figure 4. Detailed Map of Tharparkar(MAP_Tharparkar)

\section{Feasibility Analysis}

The peak load of the country occurs in June and July and during the same duration may not frequent but there are rains throughout the country which may subsequently cause a complete shutdown of solar generation but for Thar, this is not the case due to minimal rainfall and that even in month of August. Major aspects of power plant feasibility are discussed below:

\section{A. Meteorological Conditions}

This area receives adequate Direct Normal irradiance DNI throughout the year typically greater than $1650 \mathrm{kWh} / \mathrm{m}^{2}$ annually. Since the region is very dry so its relative humidity is quite low.

B. Availability of Land

1. Tharparkar is the district of the least population density in the province of Sindh'1.

2. Easy available and barren land

Tharparkar is the largest district of Sindh spread over an area of $19388.59 \mathrm{~km}^{2}$. According to the last Agriculture Census of Sindh in 2010, $464241^{2}$ acres of farms in district Tharparkar is uncultivated.

C. Accessibility of Transmission lines

There is a 247 kilometer $500 \mathrm{kV}$ (kilovolts) Thar to Matiari transmission line and thus connected to national grid. From Matiari to Lahore there is further $\pm 660 \mathrm{kV} \mathrm{HVDC}$ Line of approximately $886 \mathrm{~km}$. So has easy access to High Voltage AC as well as to High Voltage DC transmission system of the country.

\section{Adequate Road and Communication Network}

A proper road and communication network is available because of the mega Thar coal project. Each part of the district is connected with every other part and with outside through a wide interconnected road network of more than 1600 kilometers, and several other road projects are under consideration.

\section{E. Major Obstacles in Commercialization of CSP}

Future research needs to address the two major challenges in the implementation of Concentrated Solar Thermal plants on the cite of Tharparkar are: 
1. Scarcity of water and windblown sand: Tharparkar is known for the lake of water and droughts in the country. Reports suggest that out of 4791025 acres of land, there are only 59936 acres of Barrage land and rest 4731088 acres of desert land. Technologies with less water requirement or dry cooling configuration can be adopted. Studies suggest that with about a performance penalty of about $2.45 \%$, we can move for dry cooling from wet cooling configuration(Wagner \& Kutscher, 2010).

2. Soiling of Mirrors: This can be a major challenge due to windblown sand. Accumulation of sand on mirrors results in a huge decline in the optical and overall efficiency of the plant. This can be addressed either by washing the mirrors which again requires water or by adopting a self-cleaning system in which there is usually electrically sensitive plastic or glass sheet above the mirrors

Only other comparable Energy Extraction Method can be Combined Cycle Gas Turbine (CCGT) power plants, though these plants have been a far more attractive option because of its flexibility and very low LCOE, it is again not renewable though technology with less Greenhouse gas emission. The mean life cycle of Greenhouse Gas GHG emissions for Parabolic trough CSP plants is only $79.8 \mathrm{~g} \mathrm{CO}_{2}$ $/ \mathrm{kWh}$ compared to $540 \mathrm{~g} \mathrm{CO}_{2} / \mathrm{kWh}$ from combined cycle gas power plants, the only other possible option for dispatchable power generation in Pakistan(Kommalapati, Kadiyala, Shahriar, \& Huque, 2017). Furthermore, Pakistan's indigenous gas reverses are exhausting at a rapid rate and being an agriculture-based country, it must utilize its gas potential towards manufacturing of fertilizers rather than for power requirements

\section{CSP Hybrid Plants}

CSP can be integrated with Solar PV, wind, natural gas, coal, geothermal and biomass. Coal is doubtlessly a dirty fuel but cannot be eliminated at once particularly in the countries with its huge reserves. Thar has reserves of 175 billion tons of coal, making Pakistan as $7^{\text {th }}$ country having high reserves of the lignite(Malkani \& Malik, 2018) and left with almost $100 \%$ of its reserves to be extracted. Many of the major projects are seemed to be around the extraction and utilization of this indigenous mineral wealth. For now, it is almost impossible for a developing country like Pakistan to completely shift its energy resources towards renewables. Thus, reducing carbon emissions can be appreciable. The integration of CSP with the coal reduces the emissions, increases the capacity factor of Power plant and decreases the LCOE(Li et al., 2019)(Pramanik \& Ravikrishna, 2017).

Similarly, Tharparkar alone is home to more than 6 million livestock and thus feasible for Biomass generation. CSP- Biomass integration can be feasible both economically and technically for the region. This has much higher potential to address climate change(Pramanik \& Ravikrishna, 2017).

\section{Conclusion}

Concentrated solar thermal is an emerging technology and has a larger potential to serve a significant share in the overall energy mix of the country. It is particularly useful renewable where intermittency is objectionable. Stand-alone CSP or its integration with indigenous coal or Biomass can bring a considerable boost to the overall power system capacity, remove the dependency on imported fuel, accelerate the wheel of industry and reduce emissions by the transformation of Non-Renewable Technology into Low Renewable technology. Utilization of arid areas for solar power extraction can be game-changing in the field of Energy.

\section{ACKNOWLEDGEMENT}

We are highly indebted to DC Office Tharparkar for providing data of the district for useful interpretation.

\section{REFERENCES}

China Puts Online Pioneering Large-Scale CSP Project. (2018).

Hamilton, W. T., Husted, M. A., Newman, A. M., Braun, R. J., \& Wagner, M. J. (2019). Dispatch optimization of concentrating solar power with utility-scale photovoltaics. Optimization and Engineering. https://doi.org/10.1007/s11081-019-09449-y

Kommalapati, R., Kadiyala, A., Shahriar, M. T., \& Huque, Z. (2017). Review of the life cycle 
greenhouse gas emissions from different photovoltaic and concentrating solar power electricity generation systems. Energies, 10(3), 1-18. https://doi.org/10.3390/en10030350

Li, C., Zhai, R., Yang, Y., Patchigolla, K., Oakey, J. E., \& Turner, P. (2019). Annual performance analysis and optimization of a solar tower aided coal-fired power plant. Applied Energy, 237(August 2018), 440-456. https://doi.org/10.1016/j.apenergy.2019.01.003

Lilliestam, J., Barradi, T., Caldés, N., Gomez, M., Hanger, S., Kern, J., ... Patt, A. (2018). Policies to keep and expand the option of concentrating solar power for dispatchable renewable electricity. Energy Policy, 116, 193-197. https://doi.org/10.1016/j.enpol.2018.02.014

Lilliestam, J., Bielicki, J. M., \& Patt, A. G. (2012). Comparing carbon capture and storage (CCS) with concentrating solar power (CSP): Potentials, costs, risks, and barriers. Energy Policy, 47, 447455. https://doi.org/10.1016/j.enpol.2012.05.020

Malkani, M. S., \& Malik, Z. M. (2018). Coal Resources of Pakistan : entry of new coalfields Government of Pakistan Ministry of Petroleum \& Natural Resource Geological Survey of Pakistan Information Release No . 980 . Coal Resources of Pakistan : entry of new coalfields By Zafar Mahmood Issued.

MAP_Tharparkar. (n.d.). Mithi.

Mehos, M., Turchi, C., Jorgensen, J., Denholm, P., Ho, C., Armijo, K., \& National Laboratories, S. (2016). On the Path to SunShot: Advancing Concentrating Solar Power Technology, Performance, and Dispatchability. Retrieved from www.nrel.gov/publications.

Pakistan_DNI_mid-size-map_156x163mm-300dpi_v20170301.png (1842×1925). (n.d.).

Pramanik, S., \& Ravikrishna, R. V. (2017). A review of concentrated solar power hybrid technologies. Applied Thermal Engineering, 127, 602-637. https://doi.org/10.1016/j.applthermaleng.2017.08.038

Rahouma, A., El-azab, R., Adma, M. A. A. B. U., Amin, A. M. R. M. A., El, K., St, A., \& Ainy, K. El. (2017). Technical and Economic Evaluation of Concentrated Solar Power Plant 2 Concentrated Solar Power Market. 229-234.

RENEWABLE POWER GENERATION COSTS IN 2018. (2019).

Renewable Power Generation Costs in 2019. (2020). Abu Dhabi.

Saleem, S., \& ul Asar, P. D. A. (2014). Analysis \& Design of Parabolic Trough Solar Thermal Power Plant for Typical Sites of Pakistan. IOSR Journal of Electrical and Electronics Engineering, 9(3), 116-122. https://doi.org/10.9790/1676-0931116122

Soomro, Mengal, Memon, Khan, Shafiq, \& Mirjat. (2019). Performance and Economic Analysis of Concentrated Solar Power Generation for Pakistan. Processes, 7(9), 575. https://doi.org/10.3390/pr7090575

Wagner, M. J., \& Kutscher, C. (2010). The impact of hybrid WET/DRY cooling on concentrating solar power plant performance. ASME 2010 4th International Conference on Energy Sustainability, ES 2010, 2(March), 675-682. https://doi.org/10.1115/ES2010-90442

World Bank Group. (2018). Doing Business 2019: Training for Reform. World Bank. https://doi.org/10.1596/978-1-4648-1326-9 